\title{
MOB:OM: A MULTIFUNCTIONAL PREFABRICATED AND FLEXIBLE MODULE
}

\author{
P. DE BERARDINIS, C. MARCHIONNI \& L. CAPANNOLO \\ Department of Civil, Building-Architecture and Environmental Engineering (DICEAA), \\ University of L'Aquila, Italy.
}

\begin{abstract}
The current return to a logic of movement implied in human behavior and contemporary society, less static than previous generations, involves that modern architecture, in its innumerable fields of application. An effect of this is a change in the design logic of the modern construction to satisfy the requirement of the end-users of architecture more flexible and adaptable, as temporary.

The project Mob:om is a part of that, a prefabricated multifunctional module responsive to multiple needs, both functionally and dimensionally. The design concept is based on the realization of a product that, starting from the idea of a furniture, as an object container, arrives to the one of the building container of function, with the same design logic. The Mob:oM, in fact, is designed as a wooden structure that is able to hold itself and its structural, finishing and furnishing elements. It is a flexible and modular building structure whose basic module can be aggregated to other ones, allowing the growth in size, according to the spatial and functional requirements of the users: temporary events, fairs, tourist and emergency residences, exhibition stands. It is also suitable for a controlled disassembly through removable modular components: in fact, on the basis of the concept of flexibility, dry assembly techniques and stratification of constructive components have been used to allow building organism to change itself from the technological, compositive, distributive, functional and performance point of view, according to the needs of the users and the place.
\end{abstract}

The result is a multifunctional, easy to carry, reversible and modular product, characterized by an innovative design and advanced technological solutions.

Keywords: dry construction, flexibility, prefabricated modular building, sustainability.

\section{INTRODUCTION}

The resulting awareness of the relevance of temporariness within the contemporary cultural debate, both linked to emergency situations and the necessity of constant movement, is leading to a greater focus on the temporal dimension of the project and on temporary accommodation topic.

The perception of the time variable in architecture has undergone a development mainly linked to the concept of transiency, which has had, as a result, a transformation in the logic of construction, from a static and permanent dimension to a dynamic and transient one. Nowadays, in fact, we see a return to motion logic behind the human behavior, for which the contemporary society finds itself less static than past generations [1].

One of the consequences of these social dynamics is that today's architecture, in its countless fields - commerce, industry, housing, entertainment, emergency architecture - has less and less a permanent character, supporting the need for end users of a more flexible and adaptable architecture. An architecture of becoming is, thus, replacing the architecture of being and its temporary nature is leading to a change of the logic and of the project development processes.

In this context "the temporary dwelling is an important technological challenge for the future and a field of experimentation and innovation still largely to be explored. Rather than a product innovation is even stronger the need for an innovation process that establishes new conditions of employment of all current technological resources" [2]. 


\section{THE TEMPORARINESS IN ARCHITECTURE}

There are many examples, from modern to contemporary architecture that have marked the evolution of the concepts of modularity, reversibility, and transportability.

In the United States, since the beginning of 1900, many experiments on the theme of the house, conceived as a set of assembled parts, have been carried out. Typing and prefabrication, through the study of standardized cells for services, sliding walls, retractile furnishings, are the natural evolution of this trend. Among others, we acknowledge the fundamental contribution of the architect Buckminster Fuller, designer of various prototypes, linked to the myth of the machine and of the advanced technologies, like the Dymaxion House in 1929, the Dymaxion Dwelling Machine of 1946 [3]. In the twenties, in France, Le Corbusier predicted the spread of the machine for living through the development of the prototype of a new type of housing, the Maison Voisin, which integrated the concept of minimum accommodation and car [4].

In Italy, the first research related to removable and transportable structures dates back to the thirties, under the influence of the intervention plan for restocking of fascist colonies: we remember the project proposal of the architect Giuseppe Pagano in collaboration with the builder Pietro Ferrero 1937, called The Invulnerable, removable home, based on the prefabrication, Fig. 1.

In Germany, a decisive impetus for the development of studies on prefabricated houses has been supplied by the outbreak of World War II and by the consequent need for the armies to provide immediate housing troops. In those years, Walter Gropius had presented its prefabricated houses Hirsch Kupfer und Mesinwerke, while Bartning introduced the prototype Wachsende Das Haus, that could be deployed in just seven hours.

With the overcoming of the post-war period and the onset of a period of prosperity and social and economic regeneration, which marked the 50s and 60s, in America, there was a remarkable flowering of ideas and projects involving the designers of the period: a tendency based on the use of materials and extremely poor technology took place, to create new urban images in which the house had a temporary nature.

Countless project experiences developed around the world: in Japan, for example, spread the Metabolic Architecture, as an architecture in a continuous process of transformation of bodies and cells, able to grow and change in response to the environment, like the Capsule Tower (1970-1972), designed by K. Kurokawa. Finally, among the most significant European experiences, it could be mentioned the folding plastic houses designed by K.A. Rohe, the mobile home of M. Schiedhelm and the units of Alberto Rosselli and Marco Zanuso.

With the coming of the 90's, the reflection of the changes that began to take place in the world of architecture also extended to design of temporary housing buildings. The practice of
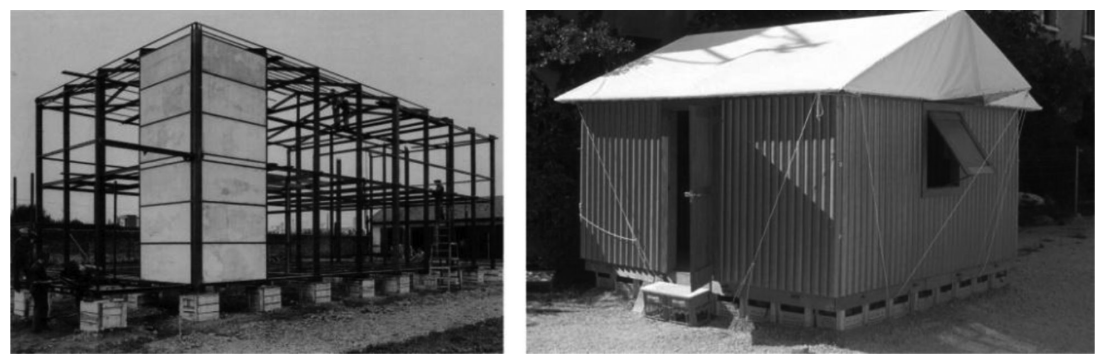

Figure 1: G. Pagano, The Invulnerable, removable home, 1937; Ban, The Log House, 1995. 
self-construction, which is the ability of the people affected by a disaster to participate in an active form to the realization of emergency settlement practice, take place, even if until then it was considered only marginally.

Hence there was a slow abandonment of finished modular systems, entirely made in workshops, in favor of more versatile mounting kits that leave a large degree of customization to the end users. The most famous example in the construction of emergency buildings is the work of a Japanese architect, Shigeru Ban, who, at the time of the disastrous earthquake of 1995 that struck Japan, designed and built a temporary accommodation, the Log House, for the earthquake victims, characterized by absolutely innovative features [5], Fig. 1.

\subsection{The construction systems for temporariness}

Many of the constructive systems for temporariness are based on the concept of serial production of basic modules, compounds of polyvalent industrialized components produced in the factory.

These, assembled on site, can be used for the construction of a different kind and category of building structures, resulting, thus, actual serial products, dimensionally combinable and interchangeable. These elements can be related to the system through internal rules and criteria, based on the concepts of transport rationalization and on the simplicity of assembling and disassembling.

The constituent parts of the resulting base system are a source of unlimited solutions and have the requirements to be integrated and correlated with each other, as the matchability and combinability.

The dry stratified constructions completely respond to these features, which consist in the stratification of structural elements able to provide individual and packet services no longer visible [6].

The building is so divisible into a bearing structure supporting the vertical and horizontal loads and in a secondary casing structure, supporting the laminated coating, internal and external, falling into the categories of dry construction defined coating-structure type [7].

The technical and performance requirements and the advantages of dry construction are well defined and closely linked to the optimization of the time, costs and the sustainability criteria.

In this respect, basic requirements are the flexibility, meant as the possible convertibility over the time of the functional and spatial attitude of the building, and the customization requirement, meant as the ability to meet the users' needs, adapting the formal, figurative and functional features to the requests.

In addition to greater flexibility and the modularity the requirements of portability and mobility are very important because, increasing the degree of freedom and adaptation of the artifact, they allow its adaptability to different environmental conditions. A transportable building, in fact, can be removed from an installation site even after long periods, generating a minimum or no impact on the environment. It allows a high probability of installation even in protected areas, hardly accessible in any other way.

It is also necessary to ensure both the rapidity of assembly and disassembly operations, and the recyclability of constructive components, meaning its ability to disassemble the building and selectively recover the constituent parts. This possibility, however, can only be ensured by the use of mechanical connections without gluing. 


\section{THE PROJECT: THE CONCEPT AND THE BASIC MODULE}

Several incentives and goals were behind the project: the first was pursuing the principles of typological-functional reversibility, temporariness, and reusability, with the aim of offering to market a multifunctional product easy to be carried, modular and technologically advanced.

Moreover, in order to pursue the energy savings, sustainable and low-powered materials and technologies have been used so as to guarantee in the same way the effectiveness cost of the final product.

The idea of using wood for the construction of a multifunctional prefabricated structure has been adopted, this solution is adaptable to different spatial and / or functional needs and attractively designed, called Mob:om, Fig. 2.

Based on the concept of flexibility and adaptability of the temporary artifact, the first design choice was to use the dry assembly techniques and the stratification of materials and building components. These choices allow the building organism to change from a technological, compositive, distributive, and functional point of view, according to the needs of the inhabitants and of the place where it is located.

The Mob:om, in fact, permits to increase its volume and its surface area in connection with the different spatial or functional needs, and it allows a quick dismantling in case of the need for a new location.

The basic module is designed as a wooden structure able to contain itself, a double- $\mathrm{C}$ in which the former, with a structural function, is able to support the latter, with closing function, when the module is opened, and to enclose it during transportation. In this way, the size of the prototype for the transport phase was considerably reduced, and the phases of assembly were facilitated, thanks to the use of modular and light elements.

Starting from the project concept, the size of the basic module is, therefore, a result of transportation needs and the requirements relating to the modularity and workability of the used materials: when the Mob:om is closed has a footprint of $(\mathrm{L} \times \mathrm{W} \times \mathrm{H}) 2,80 \times 0,90 \times$ 2,90 meters; when it is mounted, its final dimensions are $(\mathrm{L} \times \mathrm{W} \times \mathrm{H}) 2,80 \times 4,05 \times 2,90$.

In addition, from the functional point of view, the structural part provides the ability to host the zone of toilets and of plant components.

Regarding the adaptability to different contexts, however, the structure of the Mob:om is lifted from the ground thanks to the predisposition of adjustable metal pins [8].

\subsection{The construction system, materials, and connections}

For the structure of the Mob:om we have opted for the wood as the predominant construction material, because of its excellent features and specific properties. It is an easily available

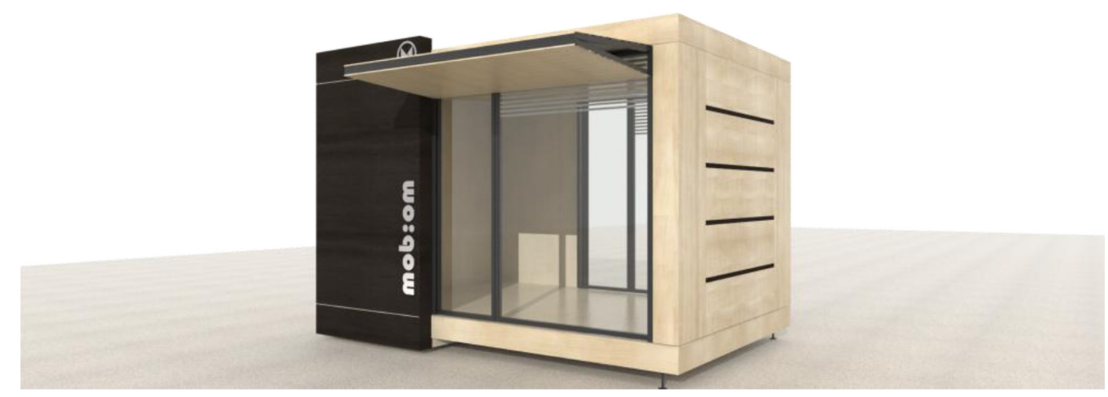

Figure 2: Photorealistic view of the project. 
material in nature in various types, which allow several figurative applications, characterized by lots of density and strength values and by a good heat resistivity, easily workable with a minimum use of energy from fossil sources.

The construction system used is with light wooden frames, in which the absorption of the loads is insured by flat linear elements with light panelling.

In the above-framed buildings, the load-bearing structure consists of a wooden frame where the pitch between the uprights, about $60 \mathrm{~cm}$, is dictated by the aim to minimize the waste due to the use of coating materials having standard dimensions on the market, usually about $125 \mathrm{~cm}$ wide [9]. Within the structure, the insulating material is placed to optimize the thicknesses of the elements, while outside the frame is covered with panels.

This type of structure ensures many advantages: the lightness of the system, the cheapness due to the easy assembly and the optimization of the material usage, beinsulation and fire protection ability, the good acoustic behaviour and good earthquake resistance.

For the structure of the Mob:om, wooden microlamellar frames in Kerto-T have been used, placed vertically at a wheelbase of about $61,5 \mathrm{~cm}$ and stiffened by means of OSB panels (oriented strandboard) $15 \mathrm{~mm}$ thick; the elements so composed are assembled together to obtain the necessary wind bracing.

Among the different types of wood, the Kerto or microlamellar (LVL-Laminated Veneer Lumber) has been chosen.

This solid material made from coniferous wood is tempered during the production process, in order to reduce and distribute the natural imperfections. In this way the resistance increase, while the deformation due to the contractions and the bulges is reduced.

The wood veneers are then glued together to form a continuous panel, subsequently cut into beams, planks or panels, whose key features are the high flexural, pressure and tensile strength, the reduction of the constructive sections and, therefore, the weight of the buildings, resulting in a reduction of the seismic actions, low deformation, ease of handling and processing and a good fire resistance [10].

In order to realize a structurally stable wood construction, great attention should be given to the design of the connection elements between the individual parts. In this case all the nodes have been realized with steel elements, using interlocking or support systems and, thus, avoiding connections by screwing, bolting or gluing. These, in fact, if repeated over time during the life cycle of the product, may weaken the structure.

The technological system was completed using wood-fibre isolation systems $100 \mathrm{~mm}$ thick between the uprights of the structural frame, covered outside with MDF Accoya wood panels.
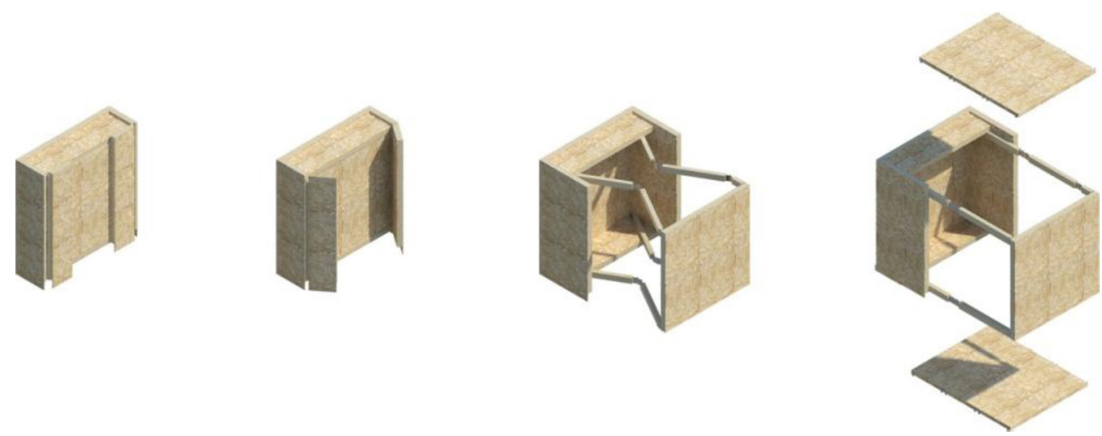

Figure 3: The opening system of the basic module. 
In this way wall elements, ceiling and roofing products can be manufactured in the factory, which allow the rapid assembly of the construction in the yard and an easy closure system for further transport.

The main feature of the Mob:om bearing system is, in fact, to allow its opening and closing after the transport to the installation site, by means of a hinged wooden beams system, which has the additional function of supporting the horizontal blanking panels. The hinges, through the use of metal plates, are also embedded in the main structure and, through the use of suitable connection systems, allow the system to be opened and closed endlessly, without causing weakening or deterioration of the structure (Fig. 4).

The horizontal coverage and paving closures, whose constructive procedure is similar to that of vertical closures, have been conceived as a set of panels wedged together by means of male-female junctions. The panels are fixed to the bearing structure by means of retractable shear bearing connections, removable and arranged on the inner side of the support beams during their phase of production.

For the covering, in addition to the stratigraphy of the floor panels, more layers, dry mounted and removable, were provided, in order to ensure the water tightness and disposal of rainwater. The shaped wooden elements of variable thickness, used to ensure an adequate slope, support an overlying layer of OSB $15 \mathrm{~mm}$, covered with a breathable membrane $0.80 \mathrm{~mm}$ thick.

For the outer and inner coating an MDF panel of Accoya wood has been added. Inside the panel, positioned in replacement of the OSB panel, guarantees a spatial continuity and chromatic uniformity, Fig. 5.

Even the transparent vertical closures are designed so as to undergo numerous assembly-disassembly cycles and in view of an easy transport on site. The constituent profiles, in fact, are characterized by reduced dimensions and extreme lightness, being made of aluminum. They are fixed by means of metallic elements predisposed during production on the main structure, permitting an easy assembly even if it was not initially designed for the installation. Finally, to avoid overheating and dazzle of the interior and, therefore, to guarantee a good level of thermal comfort and healthy sight, a knee sunscreen system was predicted, consisting of wooden strips of small thickness mounted on an aluminium frame. This system, characterized by extreme lightness and stability, can be moved manually by means of a pulley mechanism which, equipped with a braking system, guarantees a safety locking.

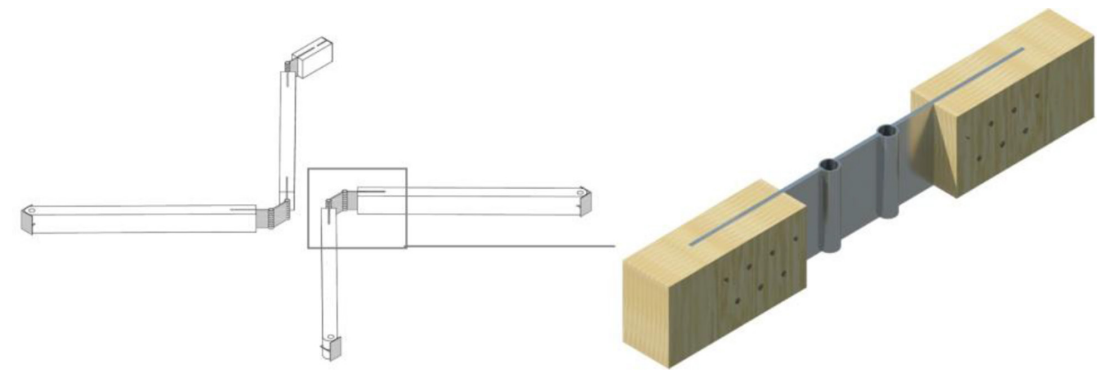

Figure 4: Hinge system drawn up for the opening of the Mob: om. 


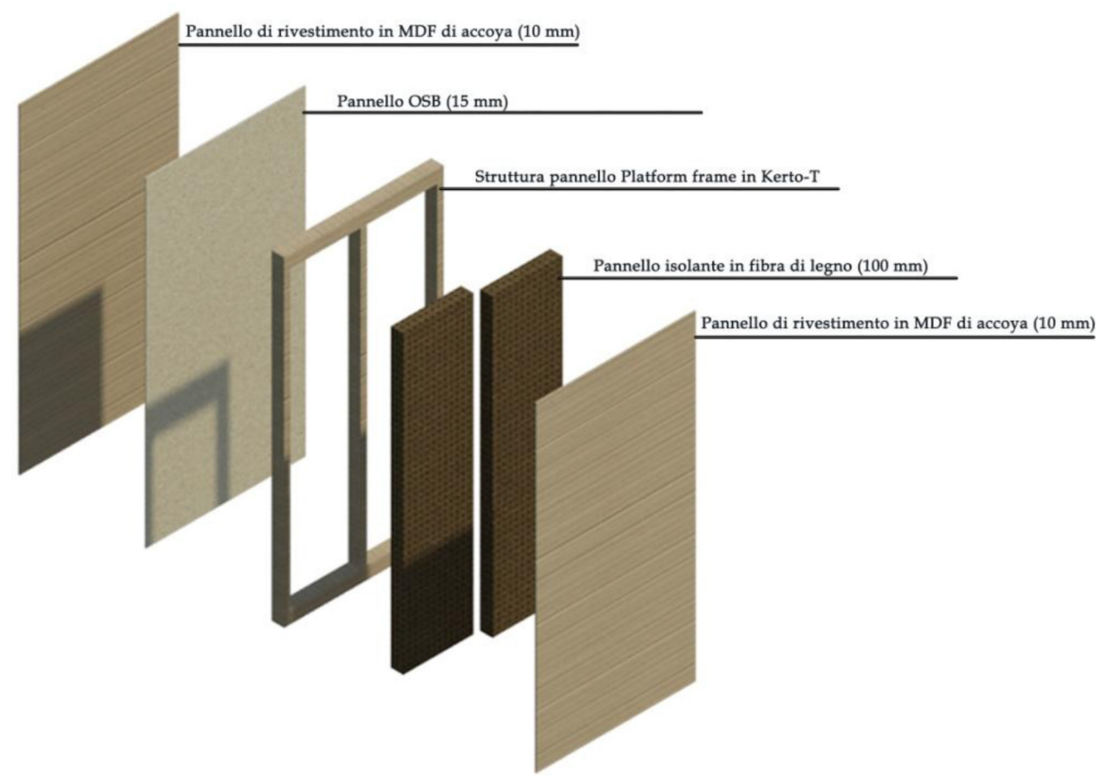

Figure 5: Stratigrafy of the vertical closure.

\subsection{Aggregation solutions and use destinations}

The aggregative solutions of the basic module can satisfy variable and temporary users. "The temporariness of living" in fact, "fulfills the need to take advantage of a space for a function associated with a contingent and the time limited need. When it ceases the space realized for that has no more reason to exist or must be converted, transformed for other uses" [2].

Trying to meet these requirements, the Mob:om is suited to different functions and utilities. So the basic module is designed to be aggregated to other modules, it can also increase in size depending on the requests. Moreover, it lends itself to a controlled disassembly thanks to the use of modular, removable and reusable components, Fig. 6.

Design hypotheses have been made considering different functional requirements and variable users on the basis of linear or staggered aggregative modality. The elements, in fact, can be aggregated on both long and short sides, taking advantage of the non-structural parts of the base module which, depending on requirements, are not completed with the glazed elements. The supposed solutions are mainly based on the aggregation of two, three and four modules, even if the system allows limitless possibilities of matchability, Fig. 7. Among the main supposed intended uses are those for tourist and emergency residences, for temporary events, fairs, exhibition stands and offices. In any case, depending on the location, the insulation system and the external covering must be designed.

Following are described the main ones:

\section{- Temporary and emergency residence}

Mob:om is designed to satisfy a temporary residential demand during emergency situations, resulting from natural disasters or big events that determine a strong increase of housing need for short periods. 

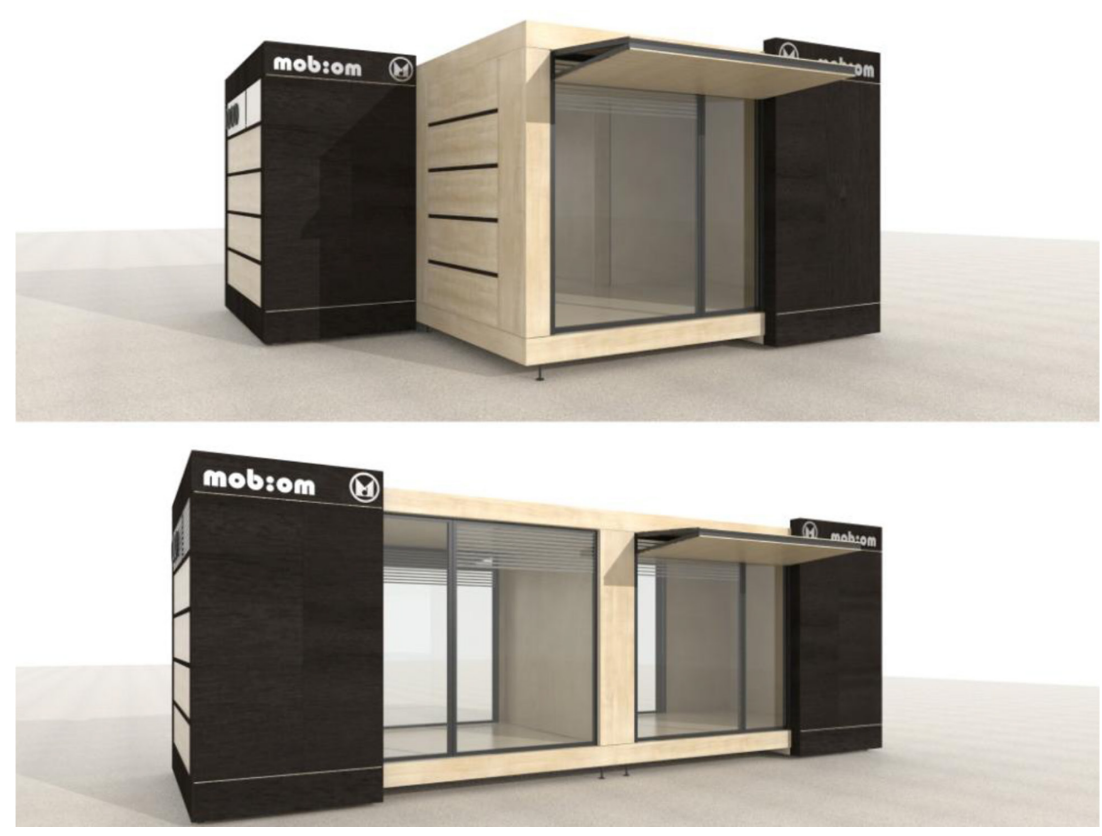

Figure 6: Different aggregative solutions.

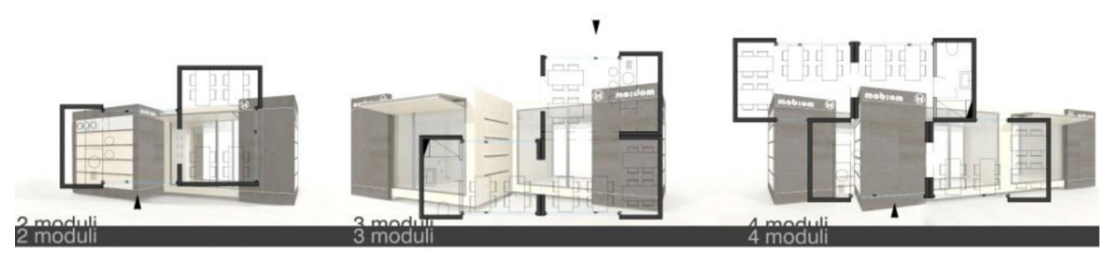

Figure 7: Some of the possible aggregative solutions with two, three and four modules.

The considered users can vary from a minimum of one to a maximum of four people.

- Tourist residence: protected areas, mountain huts, beach kiosks, campgrounds

The use of lightweight and removable structures may be the best solution to satisfy the variables of a complex tourism system, full of constraints and regulations. Thus we support the functional and housing needs of users and we minimize the settlements ecological footprint, promoting a better integration with the context.

- Temporary offices

During temporary work activities or events the Mob:om is a quick and inexpensive solution to meet the needs of the workers in the sector.

- Kiosks: café, news-stand, street selling, market, beach property

Even for these destinations the design proposal is a temporary solution that easily adapts itself to building codes and to different environmental contexts. The Mob:om, characterized by a dry assembly, allows to minimize the involved means and operators in construction operations, and it helps to lower the constructive complexity of the building, with the ability to use ordinary tools and manpower with a lower degree of specialization. 



Figure 8: The integrated furniture.

- Fair Pavilion: internal and external stands, information point

The transport and assembly rapidity of the Mob:om, combined with its attractive design and the possibility to customize it, make it suitable to propose itself as a viable solution for exhibitions or events that require the presence of an information or expositive point.

The design of the described system from the functional point was completed of view by the use of integrated furniture in the basic module, designed as containers which, through the opening and overturning systems, can be transformed in different types of requests furniture.

\section{CONCLUSIONS AND FUTURE DEVELOPMENTS}

The Mob:om project was developed with the intention to meet the contemporary needs, characterized by varied and changing users during the building life cycle.

Therefore, the Mob:om wants to establish itself in the current market, even at the economic level, ensuring the competitiveness of the final product through the production cost containment and the almost zero cost of the set-up.

The project provides the following phase of prototyping, so as to verify the functional and assembly efficiency of the designed system, to test the heat capacity of the walls, adapting them according to buyers' need, and to create different and flexible combinations.

\section{NOTES}

The research project is an initiative of the PALM scarl, manager of the Innovation Pole of Furniture, Wood, Mobile, recognized by the Abruzzo Region with D.G.R. 9/20 of 22 April 2014. The pilot project, which was aimed to realize a feasibility study, followed by its prototype, presented by Pole PALM in April 2015, was developed with the technical support of some companies participating in the consortium and it was developed in collaboration with the University of Aquila, Department DICEAA (Civil Engineering, Building and Architectural and Environmental). Designers responsible: Prof. Ing. Pierluigi De Berardinis, the project coordinator for the University of L'Aquila, Arch. Gianluca Ph.D. Buzzelli. The designers responsible for developing the project through a public selection announcement: Ing. Ph.D. Chiara Marchionni, Ing. Ph.D. Stud. Luisa Capannolo.

\section{REFERENCES}

[1] Baiocco, G., Culture della Trasformazione e della città e del territorio, Dottorato di ricerca in Progetto Urbano e Sostenibile, ciclo, p. 5, XXI.

[2] Bologna, R., Abitare la temporaneità. In Costruire in laterizio n, 126, pp. 13-15, 2008.

[3] Neder, F., Wiglley, M. \& Lam, A., Fuller Houses: R. Buckminster Fuller's Dymaxion Dwellings and other Domestic Adventures, Lars Muller Publishers: Baden, Switzerland, 2008. 
[4] Le Corbusier (author), Cerri, P., Nicolin, P. (edited by), Verso una Architettura, Longanesi, Milano, 1973.

[5] Ban, S., Shigeru Ban, Laurence King, London, 2001.

[6] Turchini, G., Tecnologie a secco: una chance in più, in Arketipo n, 14, pp. 34-35, 2007.

[7] Zambelli, E., Vanoncini, P.A. \& Imperadori, M., Costruzione stratificata a secco - Tecnologie edilizie innovative e metodi per la gestione del progetto, Maggioli Editore, Santarcangelo di Romagna, 1998.

[8] De Berardinis, P., Marchionni, C., Capannolo, L. \& Buzzelli, G., Il progetto Mob:oM. Un modulo reversibile, multifunzionale e sostenibile. In Legno earchitettura n. 23, pp.88-95, 2016.

[9] Schickhofer, G., Bernasconi, A. \& Traetta, G., Costruzione di edifici di legno. In Corso base Promo Legno - L'uso del legno nelle costruzioni, available at: www.promolegno. com.

[10] Villani, T., Tendenze innovative degli elementi in microlamellare (LVL, Kerto) per uso strutturale. In Legno e innovazione, T. Ferrante, Alinea Editrice, Firenze, 2008. 